\title{
Analysis the Transient Process of Wind Power Resources when there are Voltage Sags in Distribution Grid
}

\author{
Do Nhu $\mathrm{Y}^{1, *}$ \\ ${ }^{1}$ Hanoi University of Mining and Geology, Department of Electrification, Electromechanic Faculty, \\ Viet Nam
}

\begin{abstract}
Vietnam has many advantages of wind power resources. Time by time there are more and more capacity as well as number of wind power project in Vietnam. Corresponding to the increase of wind power emitted into national grid, It is necessary to research and analyze in order to ensure the safety and reliability of win power connection. In national distribution grid, voltage sag occurs regularly, it can strongly influence on the operation of wind power. The most serious consequence is the disconnection. The paper presents the analysis of distribution grid's transient process when voltage is sagged. Base on the analysis, the solutions will be recommended to improve the reliability and effective operation of wind power resources. Key word - wind power, transition process, reliability.
\end{abstract}

\section{Introduction}

Wind power is renewable and green energy in Vietnam. According to accounting data, Vietnam has rich wind power capacity with $8,6 \%$ area that is applicable to build up big wind power stations, among that $41 \%$ area in urban area is suitable to build small stations. Total capacity of wind power is about 513.360 MW [1]

Voltage sag is a popular phenomenon in power system that makes wind power parameters changed. Therefore analyzing the transient of wind power sources at voltage sag moments, in order to recommend suitable operation for power system containing wind power, plays an important meaning.

\section{Research method}

Nowadays, most of wind power stations utilize Double-feed-Induction-Generator (DFIG) because they have the prior advantages when stator is directly connected to the grid whereas rotor is connected to the grid through controllable power electronic devices. Because the controller in rotor, therefore its power is much smaller than the power of generator; power flows directly from stator to grid, especially with big capacity generator. In the limit range

* Corresponding author: donhuy@humg.edu.vn; donhuy.humg@gmail.com 
of speed, the power of converter is only $30 \%$ grid transmitting power. The structure of wind power generator DFIG is shown in Figure 1 [3].

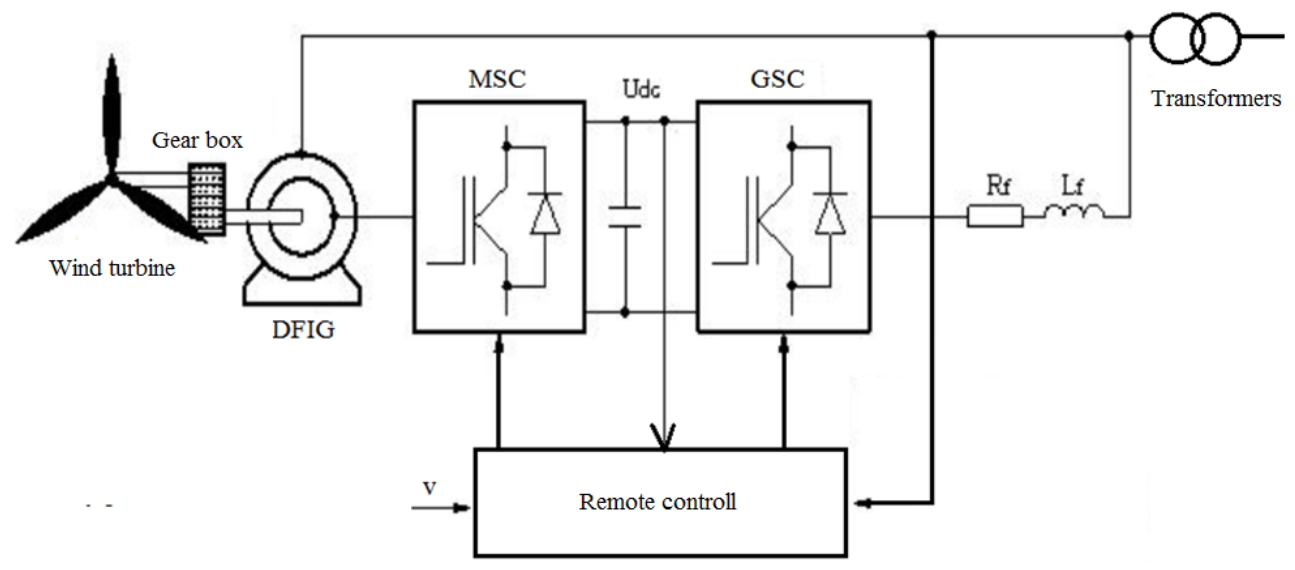

Fig. 1. Structure of wind power DFIG

In Figure 1 (MSC) is the converter on generator side used to control generator's speed in order to get maximum power. Input signals of speed controller is deducted from wind velocity. Output signals of speed controller is the ref signal for power loop controller. Grid source converter (GCS) controls DC voltage $\left(U_{d c}\right)$. It is also used to control reactive power Q.

To analyze the transient occurred in wind power when there is voltage sag, power system is simulated on Matlab-Simulink. Power generator DFIG is simulated on dq axis as Figure 2.

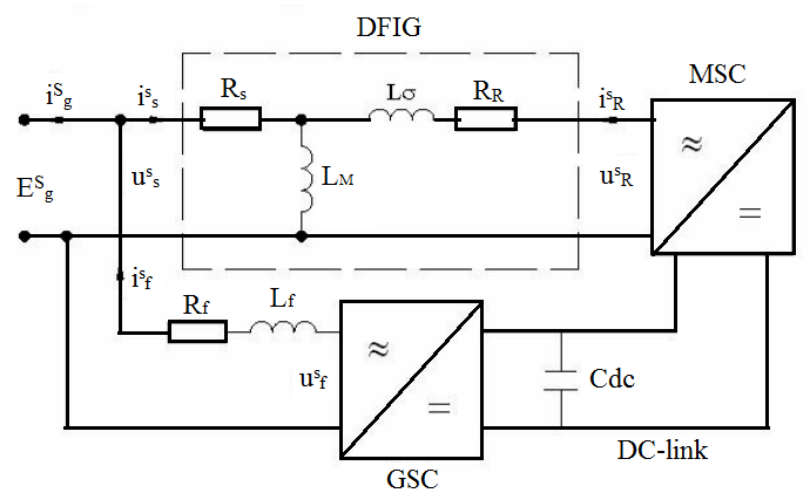

Fig. 2. Simulation of DFIG generator on space vectors

Replacing equivalent model of DIFG is expressed in stator's space vectors as shown in Figure 3.

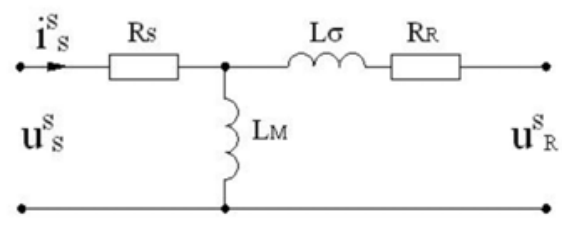

Fig. 3. Equivalent diagram of DFIG on space vector 
Where: $R_{s}$ - stator winding resistor; $L_{M}$ - Magnetic induction; $L_{\sigma}$ - Induction of statorand rotorconverted into stator side; $R_{R}-$ Rotor resistor converted to stator. Letter $s$ means space vectors ref on statorof DFIG.

According to [2], Kirchhoff equations for loop circuits:

$$
\begin{aligned}
& u_{S}^{s}=R_{S} i_{S}^{s}+\frac{\mathrm{d} \Psi_{S}^{s}}{\mathrm{~d} t} \\
& u_{R}^{s}=R_{R} i_{R}^{s}+\frac{\mathrm{d} \Psi_{R}^{s}}{\mathrm{~d} t}
\end{aligned}
$$

The fields of stator, rotor, and electromagnetic torque are computed by the following equations:

$$
\begin{aligned}
& \Psi_{S}^{s}=L_{M}\left(i_{S}^{s}+i_{R}^{s}\right) \\
& \Psi_{R}^{s}=L_{\sigma} i_{R}^{s}+L_{M}\left(i_{S}^{s}+i_{R}^{s}\right) \\
& T_{e}=3 Z_{p} I_{m}\left[\Psi_{s} i_{R}^{*}\right]
\end{aligned}
$$

Where: $L_{M}-$ Magnetizing induction; $L_{\sigma}-$ Convert induction

$$
\begin{aligned}
& L_{S}=g L_{s l}+\lambda^{2} L_{r l} \\
& \lambda=\frac{L_{s l}+L_{M}}{L_{M}}
\end{aligned}
$$

Where: $\lambda$-Convert factor; $L_{s l} ; L_{r l}$ - Induction ofstator, rotor; $Z_{p}-$ generator pole pair.

Mechanical equation of system is expressed by:

$$
\frac{J}{Z_{p}} \frac{\mathrm{d} \omega_{r}}{\mathrm{~d} t}=T_{e}-T_{s}
$$

Where: $J$ - Inertia torque; $\omega_{r}$ - rotor rotating velocity; $T_{e}$ - electromagnetic torque; $T$ mechanic torque on rotor's shaft.

Maths expression of filter on grid side includes $R_{f}$ and $L_{f}$, replace models is shown in Figure 4.

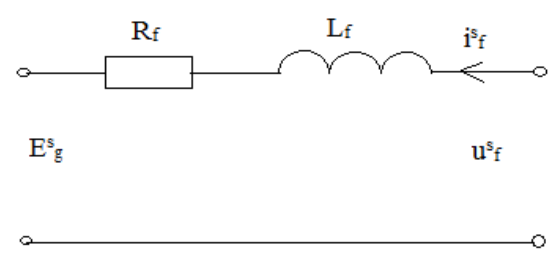

Fig. 4. Model of filter on grid side in space vector 
According to [2], Kirchhoff equation on dq axises:

$$
E_{g}^{s}=-R_{f} i_{f}^{s}-L_{f} \frac{\mathrm{d} i_{f}^{s}}{\mathrm{~d} t}+u_{f}^{s}
$$

Maths expression of DC - Link, replaced model is shown in Figure 5.

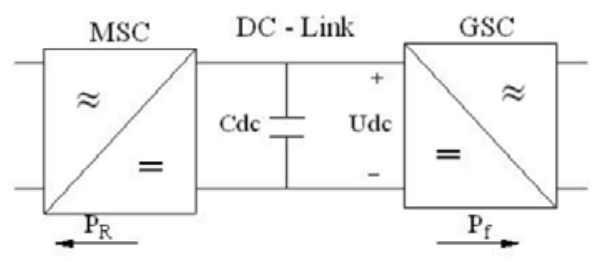

Fig. 5. Model of DC - Link

Energy $W_{d c}$ is deducted from capacitor $C$ and is computed by the following equations:

$$
\begin{aligned}
& W_{d c}=\frac{1}{2} C_{d c} U_{d c}^{2} \\
& \frac{\mathrm{d} W_{d c}}{\mathrm{~d} t}=\frac{1}{2} C_{d c} \frac{\mathrm{d}}{\mathrm{d} t} u_{d c}^{2}=-P_{f}-P_{r} \\
& C_{d c} u_{d c} \frac{\mathrm{d}}{\mathrm{d} t} u_{d c}=-P_{f}-P_{r}
\end{aligned}
$$

Output power of wind generator is calculated by:

$$
P_{m}=C_{p}(\lambda, \beta) \frac{\rho A}{2} v^{3}
$$

Where: $P_{m}$ - Output power of wind turbine; $C_{p}(\lambda, \beta)$ - power conversion factor (ratio of wing velocity $\lambda$ and wing angle $\beta$ ); $A$-cross section of; $\rho$ - air density; $v$ - wind velocity.

Power conversion factor $C_{p}$ is determined as:

$$
\begin{aligned}
& C_{p}(\lambda, \beta)=0,5176\left(\frac{116}{\lambda}-0,4 \beta-5\right) e^{\frac{21}{\lambda_{i}}}+0,0068 \lambda \\
& \frac{1}{\lambda_{i}}=\frac{1}{\lambda+0,08 \beta}-\frac{0,035}{1+\beta^{3}}
\end{aligned}
$$

Ratio of wing velocity and wind velocity is determined by:

$$
\lambda=\frac{R \omega}{v}
$$

Where: $\omega$ - Turbine rotating velocity; $R$ - Turbine radious 
On other hand wind turbine can be operated by different controlling rules base on wind velocity. Figure 6 is the expression of relation between wind turbine's power and wind velocity.

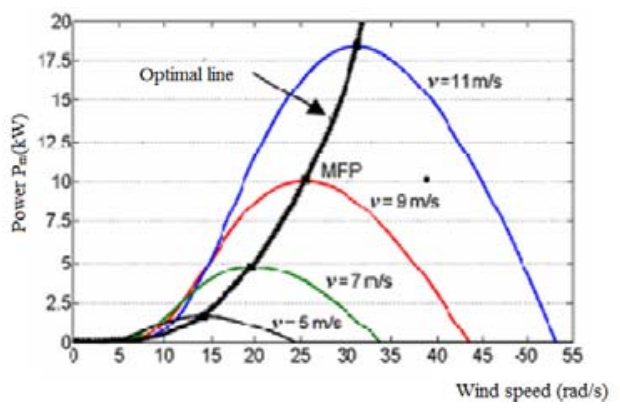

Fig. 6. The relation of wind turbine's power and wind velocity

Utilizing the simulation on Matlab-Simulink, above mentioned equations are expressed in Figure 7 [2].

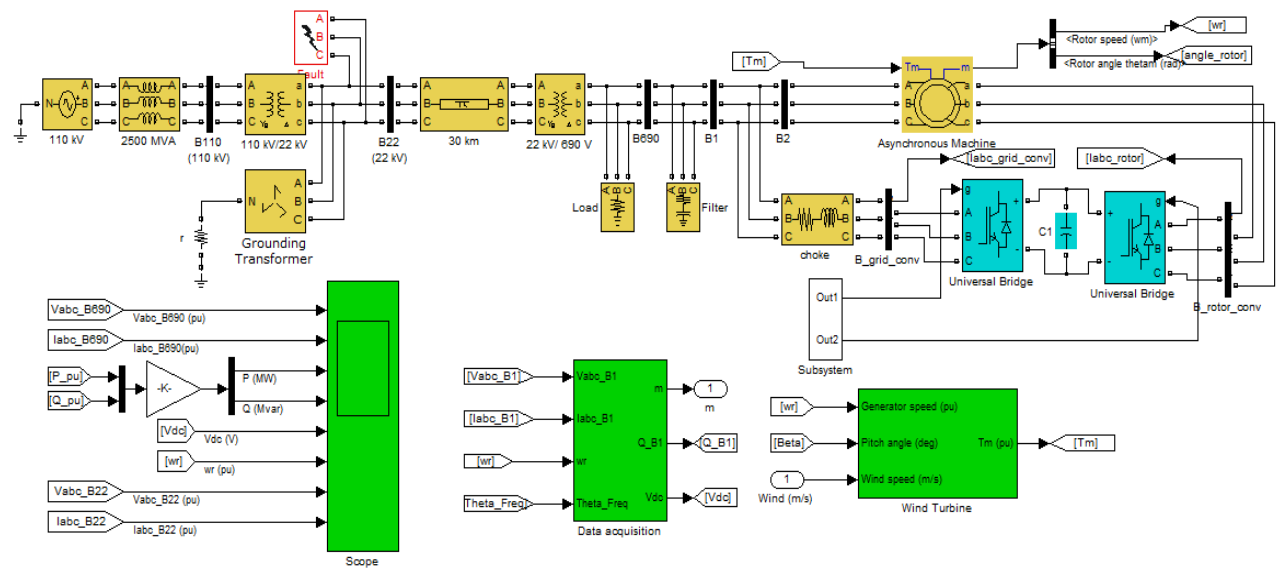

Fig. 7. Simulation diagram

\section{Results}

Simulation results are implemented on system with the following parameter: output voltage $690 \mathrm{~V}$, step-up transformer is $690 \mathrm{~V} / 22 \mathrm{kV}$, the wind power system is connected with power system on $22 \mathrm{kV}$ bus bar. In the operation of the system, there is a voltage sag, consequently voltage on $22 \mathrm{kV}$ bus bar is reduced (as shown in Figure 8 The transient process of output voltage of wind power is shown in Figure 9, the current changing is presented in Figure 10 and the transient velocity of motors is on Figure 11.

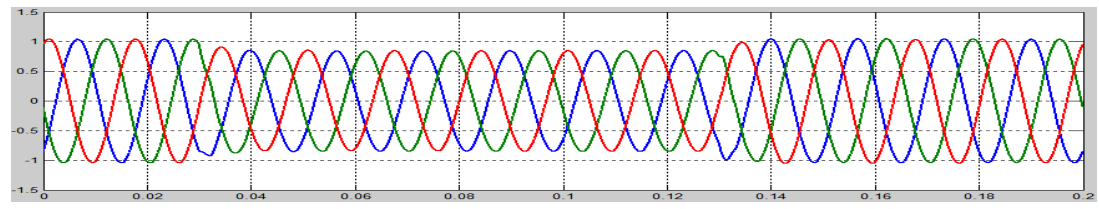

Fig. 8. Voltage on $22 \mathrm{kV}$ bus bar (B22) 


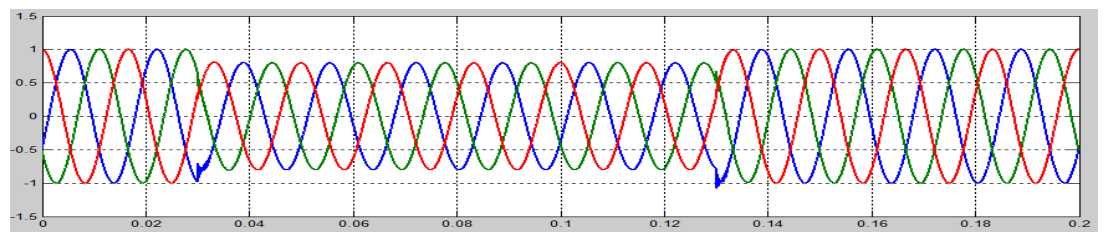

Fig. 9. Response voltage of wind power

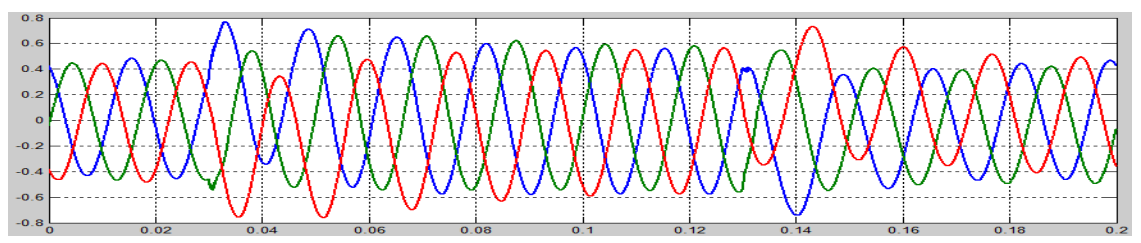

Fig. 10. Response current of wind power

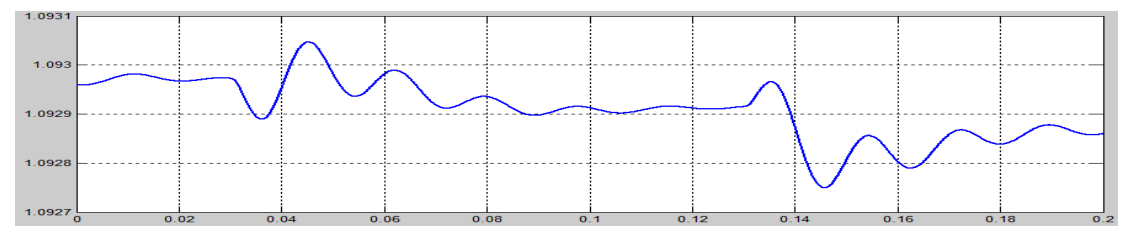

Fig. 11. The transient of generator velocity

The above simulations show that, when there is voltage sag on distribution grid $(22 \mathrm{kV}$ bus bar) output voltage of generator is also down (Fig. 9), consequently current of generator is increased (Fig. 10). If the process is long lasting can cause over load or destroy the generator. At the moment of voltage recovery, wind power voltage is also recovered, but it is transient much over rated voltage. This cause to the transient of generator velocity (Fig. 11).

\section{Conclusions}

Wind power is increased rapidly in both quantities and capacity. The Power system containing wind power resources needs a stable operation because its voltage sag could decrease the output voltage of generator. Consequently, generator's current will increase. The long lasting increasing of current could lead to over load or destroy the generator.Furthermore, at the moment of votage recovery on distribution grids, voltage is also fluctuated rapidly. The simulation results express the transient of wind power energy at the moment of voltage sag in distribution grids. The results will be used to recommended solutions for improving the stabilities, effectiveness of wind power.

\section{References}

1. Do Nhu Y, Le Xuan Thanh, Improvements to the opreation of wind power genertors in Vietnam, Journal of Vietnam Environment (ISSN-2193-6471), Vol. 8, pp. 173-178, (2016)

2. Do Nhu Y, Research using SVC to Improve the Operation of Wind Power generators in Vietnam, European of technology Journal and design, Vol. 14, pp. 159-163, (2016)

3. Lai Khac Lai, Duong Quoc Hung, Tran Thi Thanh Hai, Design the grid synchronizing controller for wind power using Double-Feed Induction Generator DIFG, Journal of Science and Technology, Vol. 10, pp. 219-225, (2010) 